\title{
Philosophiques
}

\section{Analytical Philosophy of Religion in Canada, Mostafa Faghfoury ed., Ottawa, University of Ottawa Press, 1982.}

\section{Robert Hébert}

Volume 10, numéro 2, octobre 1983

Le marxisme cent ans après Marx

URI : https://id.erudit.org/iderudit/203238ar

DOI : https://doi.org/10.7202/203238ar

Aller au sommaire du numéro

Éditeur(s)

Société de philosophie du Québec

ISSN

0316-2923 (imprimé)

1492-1391 (numérique)

Découvrir la revue

Citer ce compte rendu

Hébert, R. (1983). Compte rendu de [ Analytical Philosophy of Religion in Canada, Mostafa Faghfoury ed., Ottawa, University of Ottawa Press, 1982.]

Philosophiques, 10(2), 411-412. https://doi.org/10.7202/203238ar d'utilisation que vous pouvez consulter en ligne.

https://apropos.erudit.org/fr/usagers/politique-dutilisation/ 
Analytical Pbilosophy of Religion in Canada, Mostafa Faghfoury ed., Ottawa, University of Ottawa Press, 1982.

par Robert Hébert

Lorsque John Wisdom explore à la fin de la deuxième Guerre Mondiale les multiples sources d'une question « La croyance aux dieux est-elle raisonnable?"- avec des inimitables commentaires sur Proust, Wordsworth, Chirico, la "Monte Carlo Fallacy", le regard ornithologue de Miss Gertrud Stein, mais aussi une belle conclusion sur un verset de l'Évangile de SaintJean - , il développe à l'intérieur du wit argumentatif des penseurs britanniques ce que j'appellerais une théologie naturelle (ou une philosophie spontanée) des humeurs (cf. "Gods", Logic and Language : 1st series, ed. A. Flew, London, Blackwell, 1952, pp. 187-206). Peu à peu, avec d'autres problématiques inéluctables comme celle de la vérification/falsification des énoncés de langage issus de l'expérience religieuse et de la théologie, s'est formé un mode de penser et d'écriture extrêmement vivant qui se maintient toujours dans l'analyse du "God-talk" et que l'on retrouve ailleurs dans le "Whatevertopic-talk" de l'épistémologie, de la philosophie des sciences, de la philosophie morale. 
Cette anthologie canadienne s'inscrit dans ce courant. Son intérêt pour le lecteur contemporain réside dans le prétexte de sa composition : demander à 4 philosophes anglophones reconnus de choisir 3 textes qu'ils croient représentatifs de leur travail en philosophie de la religion, les introduire (au besoin commenter leur choix) et demander à 4 autres philosophes de commenter à leur tour leur cheminement, débattre et prendre position. Ce qui donne dans l'ordre du livre : Terence Penelhum $(1956,1970,1977)$ avec les commentaires de John King-Farlow, Kai Nielsen (1962, 1967, 1981) avec les commentaires en anglais de Benoît Garceau o.m.i., Alastair McKinnon (1960, 1967, 1972) avec les commentaires de Leslie Armour (et quelques remarques intéressantes en ce lieu sur les traditions de la théologie négative (pp. 180183), Donald Evans (1968, 1980, un inédit important intitulé "Towards a Philosophy of .Openness") avec un article en français de Jacques Poulain, professeur aux Universités de Montréal et de Picardie, qui développe les justifications nouvelles de la pragmatique judéo-chrétienne de la Révélation.

L'ensemble offre donc une perspective étonnante et variée, parfois polémique, enfermée dans un réseau géographique et précis de citations. Quant aux attitudes qui supportent le déploiement rationnel de l'analyse, beaucoup serait à dire sur les commentaires justificatifs plus ou moins autobiographiques des auteurs - en ce sens, les remarques d'un Evans qui raconte comment il a survécu aux sortilèges de Austin à Oxford pour retrouver la signification existentielle et le bien-être des métaphores organiques ("to be in tune") donnent le ton. S'il y a une qualité du livre, c'est bien l'effet d'ensemble qui déborde la spécificité flottante du titre : il y a autant de philosophies analytiques que de signatures et celles-ci nous révèlent autant de styles d'écriture brillants et hautement colorés (à faire mourir d'envie le philosophes continentaux à qui on impute d'habitude le plaisir de la thétorique) qui reviennent à leur point de départ, maintiennent des croyances de fond rationalisées dans la marge de l'opposition à la rationalité scientifique (comme le fidéisme, le théisme, diverses formes de scepticisme convivial); où la clarification des énoncés issus de l'« expérience religieuse " et de la théologie atteint rarement l'autre problème des enjeux sociaux et historiques que le "God-talk" a institué tout au long de la civilisation et dont il faudrait bien un jour mesurer le degré réel de désaliénation.

Je ne sais pas si cette anthologie est appelée à devenir un textbook pour les étudiants canadiens et québécois. Je l'espère, mais un index des noms et des matières aurait été bienvenu. Quant à l'ambiguïté de la maquette de couverture, peut-être y aurait-il eu moyen de dissiper ces naïves ombres chinoises qui symbolisent le dialogue entre les humains ? entre les religions? ou la rencontre de deux solitudes?

Département de philosophie

Collège de Maisonneuve 